\title{
Experimental investigation of reservoir sediments
}

\author{
Felix Beckers ${ }^{1,}$, Stefan Haun ${ }^{1}$, and Markus Noack $^{1}$ \\ ${ }^{1}$ Institute for Modelling Hydraulic and Environmental Systems, University of Stuttgart, \\ Pfaffenwaldring 61, 70569 Stuttgart, Germany
}

\begin{abstract}
This study presents an experimental approach to investigate cohesive reservoir sediments. It is shown, how adjacent sediment cores can be extracted from reservoir beds with a Frahm Sediment Sampler. The cores are subsequently used for detailed investigations in a hydraulic laboratory. In a first step, related cores are identified based on their bulk density profiles. One part of the related cores is used to analyze the sediment properties over depth by means of potential stability parameters. The other part is used to determine the depth-dependent erosion stability in an erosion flume (SETEG-system). In the SETEG-system, a photogrammetric method is applied to measure the erosion rates of predefined sediment layers at different exposed shear stresses. Subsequently, the critical shear stress can be derived, which leads to an objective evaluation and allows a systematic approach. Finally, both results are combined to investigate possible correlations between the evaluated depthdependent stability parameters and the measured erosion stability. The approach is presented on sediment cores from the case study "Kleiner Brombachsee", a reservoir that is located in Middle Franconia, Germany.
\end{abstract}

\section{Introduction}

Reservoir sedimentation can reduce the lifetime of reservoirs and may have negative impacts on the operation as well as on the downstream river region [1]. Thus, sustainable sediment management strategies are required to minimize reservoir sedimentation, to remobilize already deposited sediments and to restore the natural sediment continuity at its best. However, successful measures can only be derived when detailed knowledge regarding the sediment properties and the erosion stability of the deposited sediment as well as their mutual interaction exists. Moreover, depth-dependent stability information is important to address the changing sediment properties between surface layers and buried layers. In this context, especially the description of fine sediment mixtures consisting of clay, silt and sand is a challenging task due to their cohesive erosion behavior. Fine sediments, however, often dominate reservoir sediments. Therefore, this study presents an experimental approach to investigate the depth-dependent erosion stability of cohesive reservoir sediments and their sedimentological properties by taking into account physical, chemical and biological stability parameters.

\footnotetext{
*Corresponding author: felix.beckers@iws.uni-stuttgart.de
} 


\section{Material and methods}

\subsection{Study area}

The approach is presented on the case study "Kleiner Brombachsee". This reservoir was built between 1975 and 1986 as a pre-reservoir of the "Großer Brombachsee" and for the purpose of low water regulation of the Regnitz-Main catchment. It is located in Middle Franconia, Germany $\left(49^{\circ} 8^{\prime} 8^{\prime \prime} \mathrm{N}, 10^{\circ} 53^{\prime} 15^{\prime \prime} \mathrm{E}\right)$ and provides a water surface of $2.58 \mathrm{~km}^{2}$ and a total storage volume of $14.72 \mathrm{Mio}^{3} \mathrm{~m}^{3}$ at maximum operation level (411 m a.s.l.) [2].

\subsection{Collection of undisturbed sediment samples}

In a first step, adjacent sediment cores are taken from the reservoir with a so called Frahm Sediment Sampler ("Frahm-Lot"). This device was developed at the "Leibniz Institute for Baltic Sea Research" and is distributed by the "Meerestechnisches Büro Turla GmbH (MBT)" [3]. It was previously used in marine technology to close the gap between piston and gravity cores and is applied in inland waters for the first time.

With the Frahm Sediment Sampler undisturbed sediment cores with a diameter of $0.1 \mathrm{~m}$ and a length of up to $1 \mathrm{~m}$ can be extracted from the reservoir. The advantage is that a lid and a sideways movable clasp seal the sediment core immediately after removal from the bed. It can be operated from a floating platform that is equipped with a tripod and a winch. The maximum depth of operation is currently $100 \mathrm{~m}$. The sampling can be either conducted manually or electrically $(12 \mathrm{~V})$ to adapt to the present water law requirements. In the case of electric drive, the speed of the winch ranges between $20 \mathrm{~m} \mathrm{~min}^{-1}$ and $10 \mathrm{~m} \mathrm{~min}^{-1}$ (without load/with load). Fig. 1. a-c shows the jacked up Frahm Sediment Sampler with closed lid and clasp, the floating platform with the tripod equipped for operation and an extracted sediment core.

a)

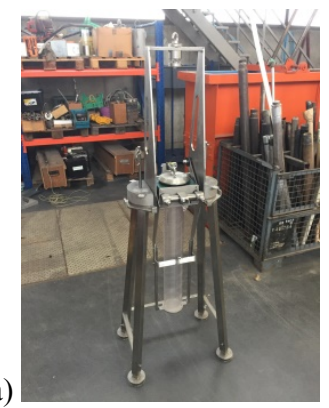

b)

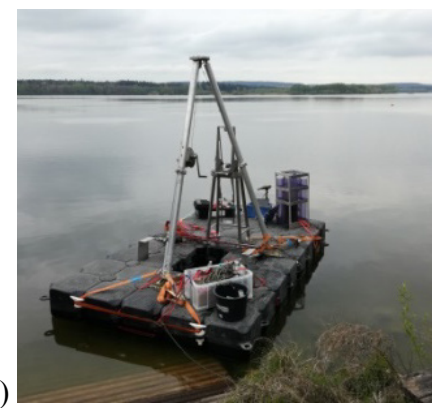

c)

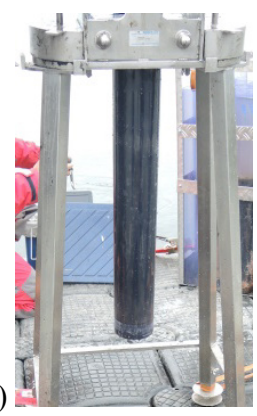

Fig. 1. a) Frahm Sediment Sampler in inactive state in the laboratory; b) equipped floating platform for the sampling of undisturbed sediment cores; c) sediment core taken with the Frahm Sediment Sampler.

\subsection{Laboratory analysis}

After their removal, the sediment cores are prepared for transportation to be analyzed in the hydraulic laboratory of the Institute for Modelling Hydraulic and Environmental Systems (IWS). The investigations in the laboratory are conducted for one core at a time. Thus, the remaining cores are vertically stored in a darkened cooling chamber to avoid any influences on the sediment layers and to reduce biological activity. 


\section{Bulk density and core allocation for destructive analysis}

First of all, the vertical bulk density profile is determined for all cores by using a nondestructive gamma-ray attenuation method. For this purpose, the sediment core is placed between a traverse system that automatically moves along the core to determine the bulk density at predefined spacing. It consists of a radioactive source of ${ }^{137} \mathrm{CS}$ with a decay energy of $662 \mathrm{keV}$ as well as a detector unit with a scintillator of Sodium Iodide doped with Thalium $(\mathrm{NaI}(\mathrm{TI})$ ) and a photomultiplier (see Fig. 2. a). The principle is to measure the absorption of gamma radiation by a penetrated media. Since the system is carefully calibrated against the attenuation of air and water, the bulk density of the sediment core can be derived.

The measurement of the bulk density profiles is the only non-destructive analysis used during the investigations. Because of that, the bulk density profiles serve as basis to identify related cores with same/similar sediment properties, to assign them to each other and to select them for the further destructive analysis. This is either the investigation of potential stability parameters or the measurement of the erosion stability. Since the cores are analyzed over depth, the bulk density profiles are also used to pre-define horizontal layers in which the further measurements take place.

\section{Sediment properties and stability parameters}

The sediment gets extracted from the cores in the pre-defined horizontal layers to be subsequently analyzed with respect to a selection of potential stability parameters. For this purpose, a construction with a lifting spindle and custom-made plugs are used to push the sediment out of the core from bottom to top. As soon as the respective layer reaches the top, three sub-samples (triplets) with a diameter of $4.5 \mathrm{~cm}$ are taken for further processing. This subdivision into triplets takes place to address the spatial heterogeneity of the sediments within a layer. After their removal, each single triplet sample is homogenized and prepared for the subsequent analyses. This leads to three representative vertical profiles of the investigated parameters along the cores.

The analyzed stability parameters included in this study are the particle size distribution (PSD), the total organic carbon (TOC), the cation exchange capacity (CEC) and to address biostabilization of cohesive sediments the extracellular polymeric substances (EPS) and Chlorophyll-a (CHL-a) [4]. The PSD is determined by laser diffraction with a Malvern Mastersizer 2000 (Malvern Instruments Ltd, Malvern, UK). The TOC is determined by loss on ignition [5], CEC by exchange with barium chloride [6], EPS proteins with the modified Lowry method [7], EPS sugars with the Dubois method [8] and CHL-a by a photometric analysis [9].

\section{Erosion stability using the SETEG-system}

Cores selected for the measurement of the depth-dependent erosion stability are analyzed with the SETEG-system of the IWS (SETEG = Strömungskanal zur Ermittlung der tiefenabhängigen Erosionsstabilität von Gewässersedimenten).

The SETEG-system was established in 2004 and has been continuously developed further to investigate the sediment stability over depth [10-11]. It consists of a straight, rectangular and closed flume, which is operated under pressurized flow. It has a total length of $8.32 \mathrm{~m}$, a width of $0.145 \mathrm{~m}$ and a height of $0.10 \mathrm{~m}$ as it can be seen in Fig. 2. b. Sediment cores are locked in position on the bottom side of the flume. The sediment sample can then be moved vertically by means of a lifting spindle. As soon as the desired sediment layer has been reached, the protruding sediment is cut off, leaving the desired layer flush with the 
bottom so the erosion test can start. During an erosion test, the sediment layer is exposed to stepwise increasing discharges of regular intervals and of constant time periods $(t=600 \mathrm{~s})$. The corresponding shear stresses are determined by a hydraulic calibration curve (Q- $\tau$ relation) that was created from high-resolution LDA-measurements in the area of interest prior to the experiment [11]. At the same time, a photogrammetric measurement of the erosion rates is conducted. For this purpose, a random grid pattern $(24,000$ points $)$ is projected on the sediment surface and surveyed by a camera (frame rate: $3 \mathrm{fps}$ ). During post-processing, images can be extracted from the recorded video of different time intervals $(\Delta t)$ and regions of interest (ROI). Surface erosion leads to a shift of the single points on the sediment surface. If erosion occurred between two images, the volume change can be calculated with a dense optical flow algorithm from the OpenCV library (https://opencv.org/). The erosion rate is subsequently calculated by dividing the detected volume by the region of interest (ROI) and by the considered time interval $(\Delta \mathrm{t})$. The optical distortion due to the angled mounting and the different penetrated media (air, glass, water) is spatially and vertically corrected by a polynomial function of second degree that was obtained during calibration experiments. The advantage of this volumetric approach is that it captures both, sediment which gets transported in suspension and sediment transported as bed load after remobilization. Moreover, the volumetric detection limit is very low and in the range of 5 to $10 \mathrm{~mm}^{3}$ per single event.

After the erosion of a sediment core, the measured erosion rates can be plotted over the corresponding shear stresses for each investigated layer separately. Based on that, the critical shear stress that serves as indicator for sediment stability can be calculated by extrapolating the shear stress for an erosion rate to $0 \mathrm{~mm} \mathrm{~s}^{-1}$ [12-15]. This allows an objective assessment of the sediment stability.

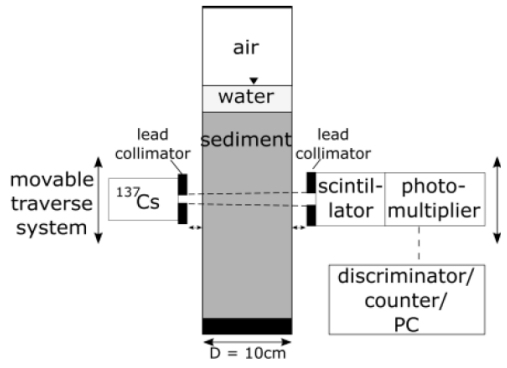

a)

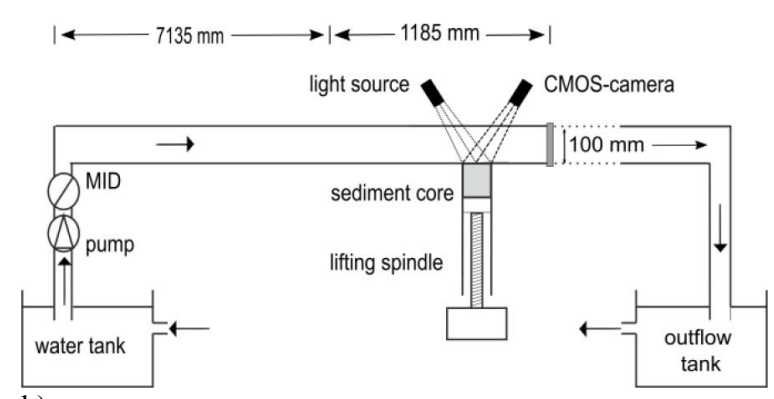

b)

Fig. 2. a) Schematic side-view of the gamma-ray densitometer and b) the SETEG-system.

\section{Combination of results}

Finally, all results of the related cores can be compared with each other to investigate the depth-dependent influence of the investigated stability parameters on the measured sediment stability. For clarification, the results are subsequently presented in a single figure as standardized values to focus on the benefits of the approach.

\section{Results and Discussion}

In total, 10 adjacent sediment cores with a sediment thickness between $0.15 \mathrm{~m}$ to $0.5 \mathrm{~m}$ were collected from the bed of the reservoir "Kleiner Brombachsee" on May 16 and May 29,2017 . The cores were collected from water depths between 4 to $5 \mathrm{~m}$ in a field of $(40 \times 25) \mathrm{m}^{2}$ close to a preservation area slightly behind the dam $\left(49^{\circ} 8^{\prime} 0.5^{\prime \prime} \mathrm{N}, 10^{\circ} 53^{\prime} 19^{\prime \prime}\right.$ 
E). At first glance it could be seen that most of the samples contain clayey material at the bottom part. The subsequent laboratory analysis revealed that this is grown soil. This led to the positive side effect that the current sediment thickness became visible $(0.05 \mathrm{~m}$ to $0.35 \mathrm{~m}$ ) and the local sedimentation rate could be calculated with the known date of impoundment (1986). Thus, the local sedimentation rate varies between $0.16 \mathrm{~cm} \mathrm{a}^{-1}$ to $1.13 \mathrm{~cm} \mathrm{a}^{-1}$.

\subsection{Bulk density and core allocation}

The results of the bulk density measurements are shown over sediment depth in Fig. 3. a. Four main characteristics can be pointed out: the profiles have different lengths according to the sediment thickness, the bulk density increases over depth, the total range of bulk densities varies between $1 \mathrm{~g} \mathrm{~cm}^{-3}$ and $2 \mathrm{~g} \mathrm{~cm}^{-3}$ and two groups can be identified due to a different characteristic increase over depth. In this context, the strong increase of the bulk density $\left(>1.7 \mathrm{~g} \mathrm{~cm}^{-3}\right)$ indicates the transition from the natural sediment into the grown soil. This means, that the natural sediment layer is very thin in the cores where this behavior occurs within the top $0.1 \mathrm{~m}$. Thus, they are excluded from further investigations leading to the remaining sediment cores shown in Fig. 3. b, which are used for the destructive analyses. For illustration purposes, the stability parameters of core "KB16-1" and the erosion stability of core "KB29-4" are presented in this study.

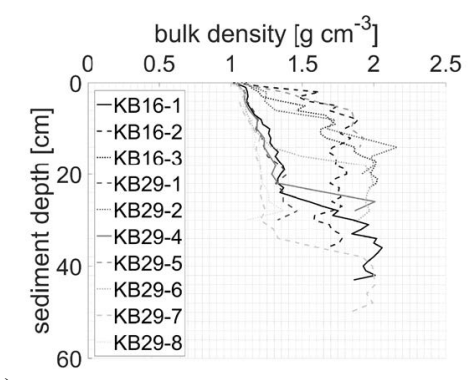

a)

a)

Fig. 3. a) Complete and b) adjusted set of bulk density profiles of adjacent sediment cores. The cores were taken from the reservoir "Kleiner Brombachsee" on May 16 and May 29, 2017 as indicated by their names.

\subsection{Sediment properties and stability parameters}

The sediment properties are investigated by means of stability parameters in different horizontal layers. The parameters PSD, TOC, CEC, EPS (separated in proteins and sugars) and CHL-a are shown for core "KB16-1" as vertical profiles in Figure 7 a-f. T1, T2 and T3 (dashed lines) represent the evaluated triplet samples within each layer, whereas the solid line shows their mean.

Fig. 4 a shows the percentile values $d_{10}, d_{50}$ and $d_{90}$ of the PSD over depth. It can be seen, that the mean of $\mathrm{d}_{10}$ and $\mathrm{d}_{50}$ decreases from top to a depth of $0.2 \mathrm{~m}$, which corresponds to a decreasing grain diameter. Below this depth, a sharp increase indicates the transition of the deposited sediment into the natural soil (see also Fig. 3). The mean of the $\mathrm{d}_{90}$ shows a pronounced peak in a depth of $0.1 \mathrm{~m}$, which is due to a high sand content in this sediment layer. Apart from that, it increases nearly constant towards the end. The mean of the TOC, CEC, EPS (proteins and sugars) and CHL-a, shown in Fig. 4 b-f, decreases over depth, apart from a few oscillations, which are mainly caused by the spatial heterogeneity of the sediments within a layer (analyzed by the triplets T1, T2 and T3). It can be clearly 
seen, that the heterogeneity reduces below $0.2 \mathrm{~m}$ (natural soil). An exception is EPS (proteins), here the reduction starts at $0.25 \mathrm{~m}$. As a result of these findings the CEC was only analyzed in the upper $0.2 \mathrm{~m}$.

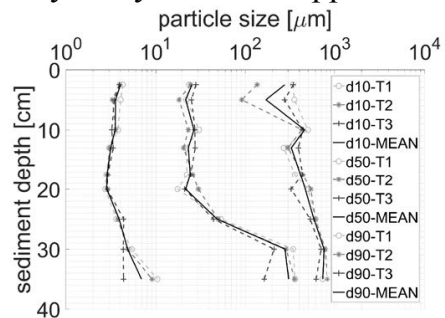

a)

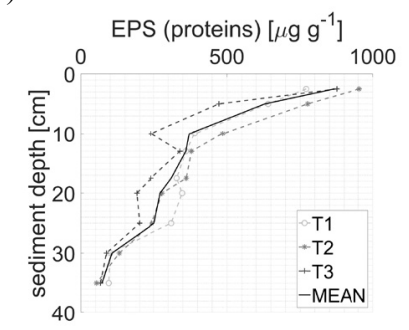

d)

Fig. 4. Vertical profiles of investigated stability parameters: a) particle size distribution (PSD) shown as percentile values $\mathrm{d}_{10}, \mathrm{~d}_{50}$ and $\mathrm{d}_{90} ; \mathrm{b}$ ) total organic carbon (TOC); c) cation exchange capacity (CEC); d) extracellular polymeric substances - proteins (EPS); e) extracellular polymeric substances sugars (EPS) and f) chlorophyll-a (CHL-a). The analyzed triplets (T1, T2 and T3) and their mean are shown.

\subsection{Erosion stability using the SETEG-system}

The results of the erosion stability tested in the SETEG-system are shown in Fig. 5 for core "KB29-4". The core is eroded at seven layers $(4 \mathrm{~cm}, 7 \mathrm{~cm}, 10 \mathrm{~cm}, 13 \mathrm{~cm}, 16 \mathrm{~cm}, 19 \mathrm{~cm}$ and $22 \mathrm{~cm}$ ). During the erosion test, the measured erosion rates are used to determine the critical shear stress for each layer by calculating the shear stress for an extrapolated erosion rate of $E=0 \mathrm{~mm} \mathrm{~s}^{-1}$.

It can be seen, that in the first two layers, the critical shear stress and the sediment stability is comparatively low (around $0.3 \mathrm{~N} \mathrm{~m}^{-2}$ ). In the next two layers a strong increase occurs to the maximum stability of $\tau_{\text {crit }}=1.27 \mathrm{~N} \mathrm{~m}^{-2}$, reached at a depth of $0.13 \mathrm{~m}$. A following decrease to the end is interrupted by another raise at a depth of $0.19 \mathrm{~m}$. It is likely, that the "younger" sediment on top is easier to remobilize, whereas the deeper located sediment layers are consolidated and thus more stable. The low value in the last layer might already indicate the sandy natural soil (see also Fig. 3.).

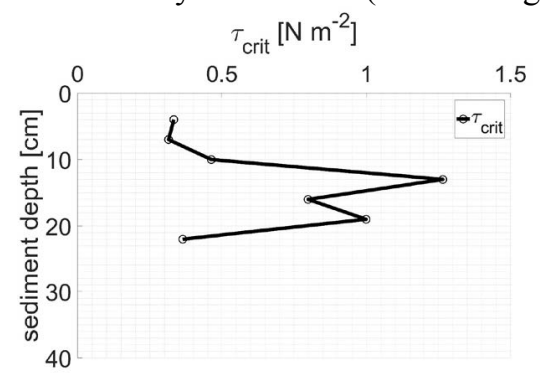

Fig. 5. Depth-dependent sediment stability of core "KB29-4" expressed as critical shear stress. 


\subsection{Combination of results}

In a next step, the vertical profiles of the stability parameters and of the erosion stability can be compared with each other to investigate possible relationships. The results are presented as normalized values in Fig. 6 .

Fig. 6. a shows the physical stability parameters ("KB16-1") and the measured erosion stability of core "KB29-4". It can be seen for instance, that the local increase in $\mathrm{d}_{90}$ at a depth of $0.1 \mathrm{~m}$ corresponds to a relative low erosion stability. Vice versa, the following decrease of $d_{90}$ in the layer below $(0.13 \mathrm{~m})$ leads to a significant higher erosion stability. This can be explained with a decreasing particle size and an increasing cohesiveness in the sediment layer at $0.13 \mathrm{~m}$ leading to a higher sediment stability.

Fig. 6. b shows the chemical and biological stability parameters ("KB16-1") and the measured erosion rate of core "KB29-4". Here, the decreasing trend of the stability parameters can be seen. However, at the highest measured shear stress in the layer at $0.13 \mathrm{~m}$ a local peak is discernible. Here the chemical and biological parameters may additionally reinforce the stabilizing effect induced by the physical parameters and finally contribute to the increased stability. However, further investigations are necessary to reveal these interactions.

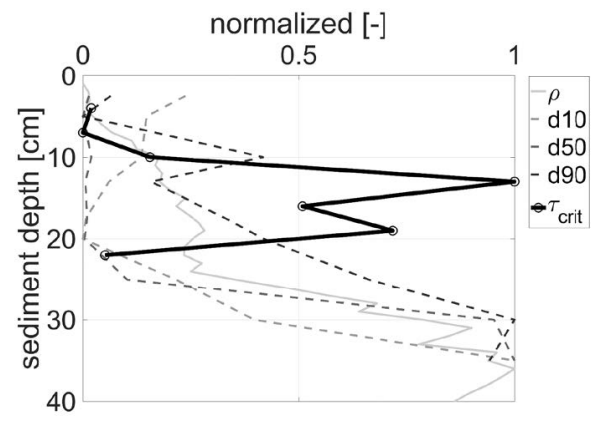

a)

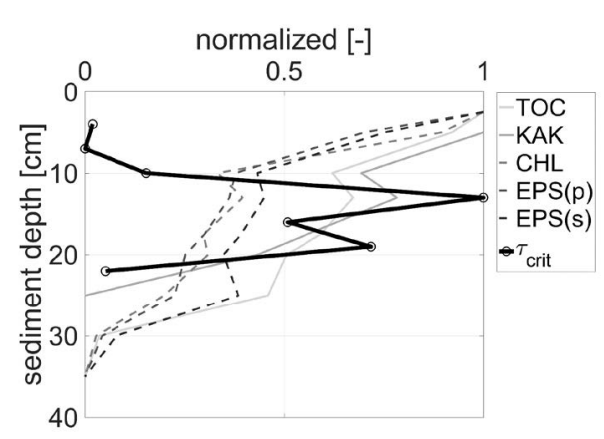

b)

Fig. 6. a) Combination of physical stability parameters ("KB16-1") and b) chemical and biological stability parameters ("KB16-1") with the measured erosion stability of core "KB29-4". All results are shown as normalized values.

\section{Conclusions}

In this study, an experimental approach to investigate cohesive reservoir sediments is presented. For this purpose, undisturbed sediment cores are successfully extracted from the reservoir bed with a Frahm Sediment Sampler. They are used to investigate the depthdependent sediment properties and the erosion stability in laboratory analyses. The investigated stability parameters (particle size distribution (PSD), total organic carbon (TOC), cation exchange capacity (CEC), extracellular polymeric substances (EPS proteins and EPS sugars) and Chlorophyll-a (CHL-a)) are compared with the erosion stability, determined with the SETEG-system to examine possible correlations.

It can be seen for the cores obtained from the case study "Kleiner Brombachsee", that there is a negative visual correlation between the $d_{90}$ and the sediment stability in some of the investigated top layers. In addition, reinforcement due to chemical and biological stability parameters is likely but must be further investigated. In the lower layers no visual correlation can be found. 
In general, the presented approach is applicable to investigate reservoir sediments, to describe their properties, their erosion stability and to identify key-parameters that govern cohesive sediment stability. Finally, this information can be used to derive site-specific sediment management strategies for sustainable reservoir operation.

This study was conducted within the project CHARM - Challenges of Reservoir Management Meeting Environmental and Social Requirements. The project is part of the Water Research Network Baden-Württemberg. It is funded by the Ministry of Science, Research and Arts of the federal state of Baden-Württemberg, Germany.

\section{References}

1. G.L. Morris, J. Fan, Reservoir sedimentation handbook: design and management of dams, reservoirs, and watersheds for sustainable use (McGraw-Hill, New York, 1998)

2. Deutsches TalsperrenKomitee e. V. (Ed.), Talsperren in Deutschland (Springer Fachmedien Wiesbaden, Wiesbaden, 2013)

3. Reikowski, A., Manual FRAHM-LOT, (MBT Underwater Technology, V 1.1)

4. S.U. Gerbersdorf, S. Wieprecht, Biostabilization of cohesive sediments: revisiting the role of abiotic conditions, physiology and diversity of microbes, polymeric secretion, and biofilm architecture, Geobiology 13, 68-97 (2015)

5. DIN EN 13137:2001-12, Characterization of waste - Determination of total organic carbon (TOC) in waste, sludges and sediments (2001)

6. DIN ISO 13536:1997-04, Soil quality - Determination of the potential cation exchange capacity and exchangeable cations using barium chloride solution buffered at $\mathrm{pH}=$ 8,1 (ISO 13536:1995) (1997)

7. K. Raunkjaer, T. Hvitvedjacobsen, P.H. Nielsen, Measurement of pools of protein, carbohydrate and lipid in domestic waste-water, Water research 28, 251-262 (1994)

8. M. Dubois, K.A. Gilles, J.K. Hamilton, P.A. Rebers, F. Smith, Colorimetric method for determination of sugars and related substances, Analytical chemistry 28, 350-356 (1956)

9. DIN 38412-16:1985-12, German standard methods for the examination of water, waste water and sludge; test methods using water organisms (group L); determination of chlorophyll-a in surface water (L 16) (1985)

10. O. Witt, B. Westrich, Quantification of erosion rates for undisturbed contaminated cohesive sediment cores by image analysis, The Interactions between Sediments and Water. Springer, pp. 271-276 (2003)

11. M. Noack, S.U. Gerbersdorf, G. Hillebrand, S. Wieprecht, Combining Field and Laboratory Measurements to Determine the Erosion Risk of Cohesive Sediments Best, Water 7, 5061-5077 (2015)

12. A. Schaefer Rodrigues Silva, G. Schmid, M. Noack, S. Wieprecht, Erosionsmessungen an Sedimentkernen aus dem Oberwasser der Wehranlage Marckolsheim und Rhinau (No. 03/2017), Institut für Wasser- und Umweltsystemmodellierung (2017)

13. T.M. Ravens, P.M. Gschwend, Flume measurements of sediment erodibility in Boston Harbor, Journal of Hydraulic Engineering 125, 998-1005 (1999)

14. L.P. Sanford, J.P. Halka, Assessing the paradigm of mutually exclusive erosion and deposition of mud, with examples from upper Chesapeake Bay, Marine Geology 37-57 (1993)

15. T.J. Tolhurst, R. Riethmüller, D.M. Paterson, In situ versus laboratory analysis of sediment stability from intertidal mudflats, Continental Shelf Research (2000) 